\title{
Púrpura trombocitopénica secundaria a COVID-19
}

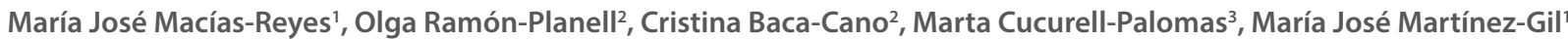 \\ 'Servicio de Urgencias. Hospital General de Igualada. Igualada (Barcelona). España \\ ${ }^{2}$ Servicio de Hematología. Hospital General de lgualada. Igualada (Barcelona). España \\ ${ }^{3}$ Servicio de Dermatología. Hospital General de lgualada. Igualada (Barcelona). España
}

Recibido:24/05/2020

Aceptado: 28/07/2020

En línea: $31 / 08 / 2020$

Citar como: Macías-Reyes MJ, Ramón-Planell O, Baca-Cano C, Cucurell-Palomas M, Martínez-Gil MJ. Púrpura trombocitopénica secundaria a COVID-19. Rev Esp Casos Clin Med Intern (RECCMI). 2020 (Ago); 5(2): 100-102. doi: 10.32818/reccmi.a5n2a15.

Cite this as: Macías-Reyes MJ, Ramón-Planell O, Baca-Cano C, Cucurell-Palomas M, Martínez-Gil MJ. Thrombocytopenic purpura secondary to CovID-19. Rev Esp Casos Clin Med Intern (RECCMI). 2020 (Ago); 5(2): 100-102. doi: 10.32818/reccmi.a5n2a15.

Autor para correspondencia: María José Macías-Reyes. mariaj_1793@hotmail.com

\section{Palabras clave \\ $\triangleright$ Púrpura \\ $\triangleright$ Trombocitopenia \\ $\triangleright$ SARS-COV-2}

\section{Resumen}

Paciente con lesiones purpúricas y plaquetopenia severa de 2,0 × 10\%/. Como síntomas respiratorios sólo refería disnea. En la ecografía clínica presentaba líneas B en varios campos pulmonares sugestivas de condensación neumónica bilateral, corroborada radiográficamente. La PCR para SARS-CoV-2 fue positiva. Los resultados analíticos nos permitieron concluir que era una púrpura trombocitopénica inmunitaria (PTI) ocasionada por dicho virus.

Se instauró tratamiento con hidroxicloroquina + lopinavir/ritonavir y, para la PTI, metilprednisolona e inmunoglobulina hasta que remitieron las lesiones, desapareció la disnea y aumentaron las plaquetas. Posteriormente precisó tratamiento con eltrombopag para normalizar las cifras plaquetarias.

\begin{tabular}{l} 
Keywords \\
\hline$\triangleright$ Purpura \\
$\triangleright$ Thrombocytopenia \\
$\triangleright$ SARS-CoV-2
\end{tabular}

Abstract
Patient with purpuric lesions and severe platelet disease of $2.0 \times 10^{\circ} / \mathrm{L}$. About respiratory symptoms he only re-
ferred dyspnea; on clinical ultrasound, we found B lines in several lung fields suggestive of bilateral pneumonic
condensation, confirmed radiographically. SARS-COV-2 PCR test was positive. The analytical results allowed us
to conclude that it was immune thrombocytopenic purpura (ITP) due to that virus.
Treatment with hydroxychloroquine + lopinavir/ritonavir was initiated, also, methylprednisolone and immu-
noglobulin. The lesions remitted, the dyspnea disappeared and platelets increased. Subsequently, he required
treatment with eltrombopag, which normalized platelet count.

\section{Puntos destacados}

$\triangleright$ Ante una púrpura trombocitopénica debemos descartar como posible etiología la infección por SARS-CoV-2.

$\triangleright$ En nuestro paciente, la COVID-19 no produjo trombocitopenia en fases avanzadas de la infección en forma de coagulación intravascular diseminada sino mediante un mecanismo inmunológico.

\section{Introducción}

La COVID-19 es el nombre de la enfermedad causada por el coronavirus tipo 2 del síndrome respiratorio agudo grave (SARS-CoV-2). Los síntomas más comunes son fiebre, astenia, tos seca y disnea. También anosmia, disgeusia, odinofagia, náuseas o diarreas'. Se ha asociado a alteraciones en las pruebas de coagulación en forma de plaquetopenia compatible con trombocitopenia inmune $(\mathrm{PTI})^{2}$.

Una infección vírica puede ocasionar una PTI mediante un mecanismo inmunitario o por su afectación directa sobre las plaquetas y megacariocitos.

Otros virus como el citomegalovirus, el virus Epstein-Barr, la hepatitis B o el virus de la inmunodeficiencia humana $(\mathrm{V} / \mathrm{H})$ también pueden ocasionar trombocitopenia como consecuencia de una respuesta inmunitaria inadecuada.

Asimismo, otros virus como el rinovirus, el herpes, el adenovirus o el coxsackie pueden alterar el número y la función plaquetaria. 


\section{Caso clínico}

\section{Antecedentes}

Varón de 67 años con antecedentes de hipertensión arterial, cardiopatía isquémica, portador de dos stents en tratamiento con ácido acetilsalicílico, insuficiencia renal crónica estadio III y enfermedad pulmonar obstructiva crónica estadio GOLD B tratada con bromuro de tiotropio. Consultó por aparición de lesiones hemorrágicas en labio superior, paladar y lengua, y lesiones purpúricas en hombros, brazos y espalda. Además, presentó aumento de la disnea pasando de grado II a III de la clasificación de la New York Hearth Association (NYHA), sin fiebre ni tos. No había visualizado hemorragias a otros niveles. Negaba incumplimiento ni sobredosis terapéutica.

\section{Exploración física}

Su estado general era bueno: eupneico, frecuencia respiratoria de $16 \mathrm{rpm}$, hemodinámicamente estable con tensión de 163/96 mmHg, frecuencia cardíaca de 61 lpm, afebril y sin palidez cutánea. No hepatoesplenomegalia. Presentaba lesiones petequiales y equimóticas en mucosa oral, labio superior y paladar (Figura 1 y Figura 2).

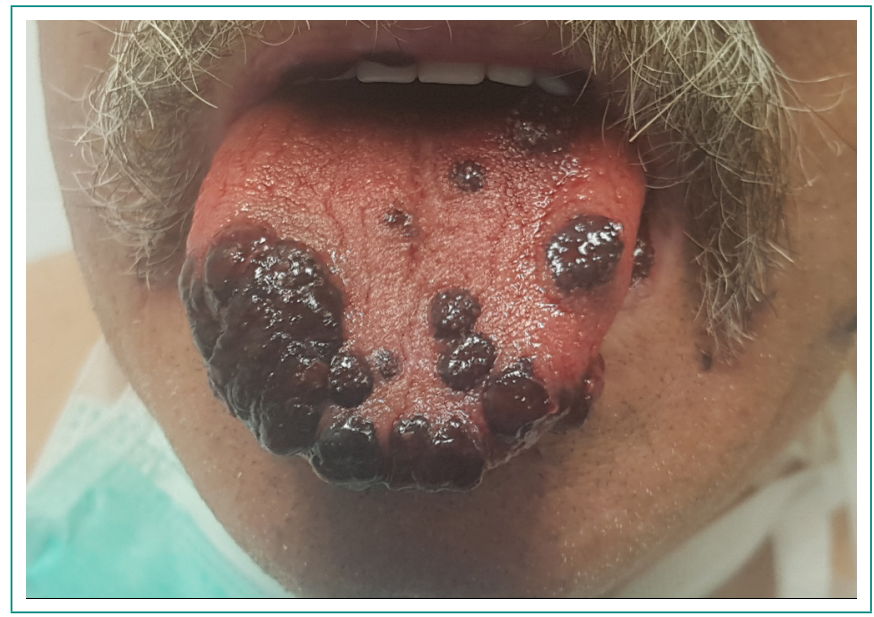

Figura 1. Lesiones petequiales en lengua

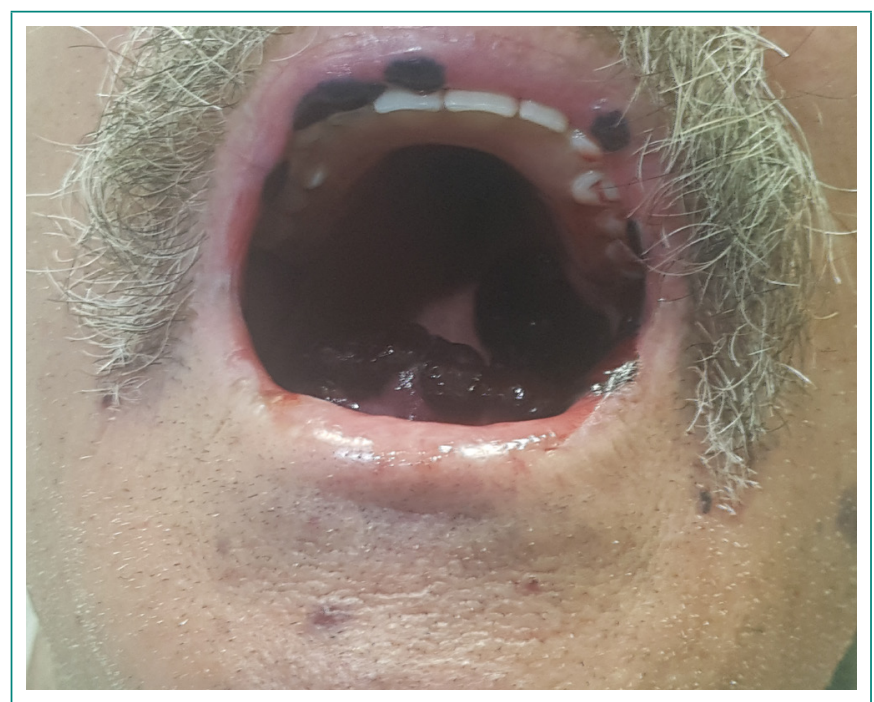

Figura 2. Lesiones en labio superior y paladar
En piel también tenía petequias (lesiones maculares eritematosas que no desaparecían a la vitropresión, de 3-4 mm de diámetro aproximado) con distribución en brazos, hombros y parte superior de espalda (Figura 3).
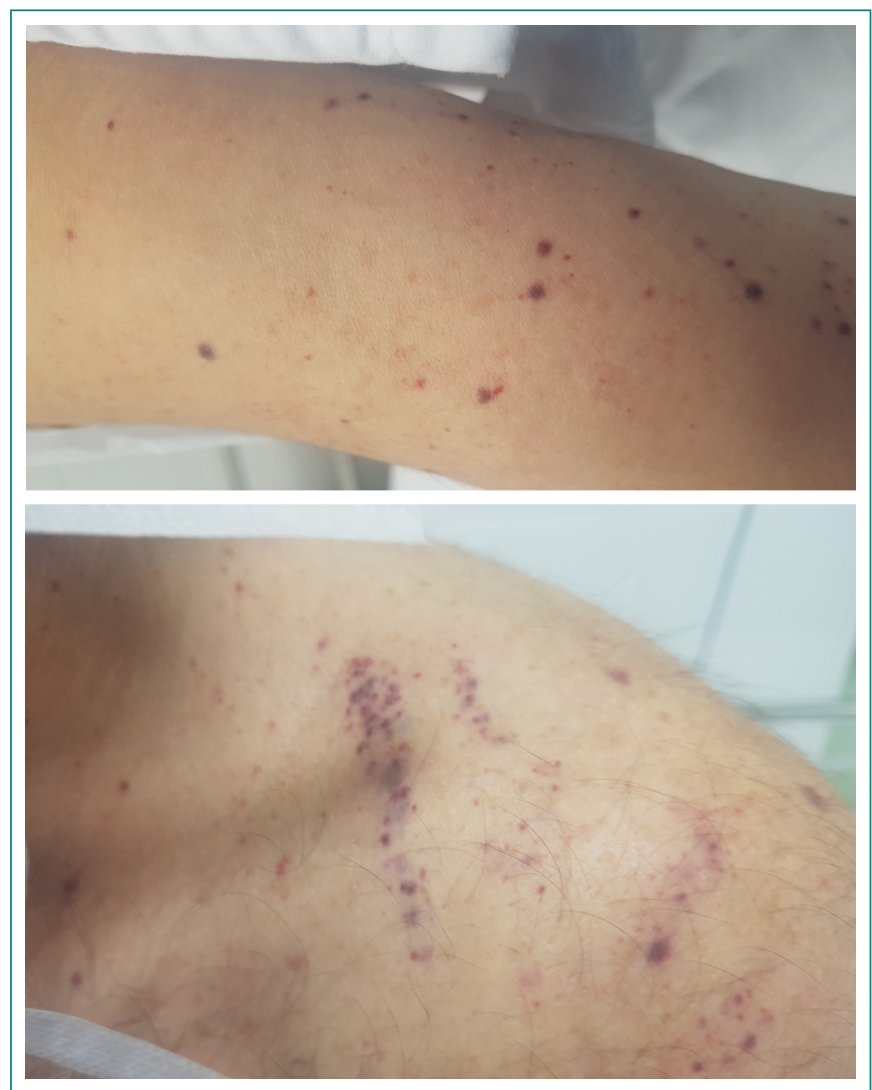

Figura 3. Lesiones purpúricas en miembros superiores

\section{Pruebas complementarias}

Por el aumento de la disnea, realizamos ecografía clínica y presentaba líneas B con deslizamiento pleural normal (perfil B), compatibles con infiltrados bilaterales parcheados, corroborado radiográficamente (afectación sugestiva de COVID-19) por lo que se efectuó prueba de reacción en cadena de polimerasa (PCR) de SARS-CoV-2 positiva en frotis nasofaríngeo. La neumonía presentaba un riesgo medio por tener un FINE III y 1 punto en la escala pronóstica CURB-65.

Analíticamente, en el hemograma destacaban 2,0 × 10\% / plaquetas (140-400 $\left.\times 10^{9}\right)$, con 4,07 x $10^{9}(3,90-9,50)$ leucocitos con fórmula normal, hemoglobina y volumen corpuscular medio normales. El estudio de la coagulación fue normal: tiempo de protrombina (TP) 100\%, INR 0,90, tiempo de tromboplastina parcial activado (TTPA) 23,7 s. D-dímero de $1.630 \mathrm{ng} / \mathrm{ml}(<500)$ y fibrinógeno elevado. En la bioquímica presentaba un filtrado glomerular de $40 \mathrm{ml} / \mathrm{min}$ (> 90) y creatinina de $1,7 \mathrm{mg} / \mathrm{dl}(0,7-1,3)$, similares a previos. La proteína C reactiva era de $12 \mathrm{mg} / \mathrm{l}(<3)$ y la procalcitonina no estaba elevada.

Se completó el estudio de trombocitopenia; en la revisión del frotis de sangre periférica no se observaron agregados plaquetarios, esquistocitos ni células inmaduras o atípicas; sí algún linfocito estimulado compatible con proceso viral. La fracción de plaquetas inmaduras era del 1,2\%.

El Coombs directo fue negativo, con bilirrubina y lactato deshidrogenasa normales. El porcentaje de reticulocitos fue del 0,8\% (41.300 × 10\%/l). La haptoglo- 
bina estaba elevada a $240 \mathrm{mg} / \mathrm{dl}$ (30-200), probablemente reflejando el contexto inflamatorio, al igual que la ferritina de $1.032 \mu \mathrm{g} / \mathrm{l}(8-252)$.

Las proteínas totales eran 8,2 g/l (6,4-8) y en el proteinograma se evidenciaba una elevación importante de la fracción de gammaglobulina del 40\% (11,118,8), con aumento de inmunoglobulina G (lgG) de 3.420 mg/dl (700-1.600). La determinación por inmunoanálisis de anticuerpos lgG de SARS-CoV-2 fue positiva, con un índice de 4,76 (significativo si > 1,1).

Respecto a la autoinmunidad, los anticuerpos antinucleares y antimitocondriales fueron negativos y los anticitoplasmáticos, positivos. Las serologías de VIH, hepatitis B y C fueron negativas.

\section{Evolución}

Se orientó como neumonía bilateral por SARS-CoV-2 con púrpura trombocitopénica grave, probablemente secundaria a dicha infección, por lo que se inició tratamiento con metilprednisolona 100 mg diarios + inmunoglobulina a dosis de $1 \mathrm{~g} / \mathrm{kg}$ durante 2 días; y tratamiento para la COVID-19, según lo definido en el protocolo hospitalario: lopinavir/ritonavir + hidroxicloroquina + azitromicina. A las 24 horas había presentado mejoría de las lesiones, sin signos de sangrado, y de las plaquetas, pasando a $4,0 \times 10^{9} / \mathrm{l}$.

Tras 8 días de ingreso y completar el tratamiento, el paciente presentó una evolución favorable con mejoría clínica y remisión de las lesiones orofaríngeas y de piel. Se le dio el alta con 39.000 plaquetas y una fracción de plaquetas inmaduras aumentada al 20\%. Se le pautó tratamiento con prednisona 90 mg/ día y seguimiento con Hematología.

En el control 6 días tras el alta se detectó una nueva disminución de la cifra plaquetaria hasta $18.000 \times 10^{9} /$, sin signos de sangrado ni de infección. El TP y TTPA permanecían normales, y la cifra de D-dímero había aumentado a 2.790. Se inició tratamiento con eltrombopag a dosis de 50 mg/día. Una semana posterior al inicio de dicho tratamiento la cifra de plaquetas se había recuperado a $80.000 \times 10^{\%} /$, con una fracción de plaquetas inmaduras del 11\%. Destacaba la disminución en el proteinograma de la fracción de gammaglobulina a un 25\% y la lgG se había normalizado a 1.390 mg/dl. Tras 2 semanas, las plaquetas normalizaron a $210.000 \times 10^{9} / 1$.

\section{Diagnóstico}

Púrpura trombocitopénica inmunitaria con neumonía debida a la infección vírica por SARS-CoV-2, probablemente mediada por la respuesta inmunológica a la infección vírica.

\section{Discusión y conclusión}

La incidencia de trombocitopenia para el SARS-CoV-1 es del 20-55\% $\%^{3}$, mientras que para el SARS-CoV-2 resulta aún desconocida. Tang et al. ${ }^{4}$ reportaron un $57,1 \%$ de trombocitopenia en pacientes fallecidos por neumonía secundaria a SARS-CoV-2, correlacionándose con un incremento del riesgo de enfermedad severa. El mecanismo más probable sería el consumo de factores de coagulación en el contexto de coagulopatía por sepsis o infección grave.

Se han descrito alteraciones de las pruebas de coagulación, como trombocitopenia habitualmente leve, y con niveles elevados de D-dímero. La respuesta inflamatoria de los macrófagos a nivel del alvéolo pulmonar produciría una cantidad elevada de citocinas. La liberación de factor tisular activaría la producción de trombina y, por otra parte, el aumento de los niveles del activador tisular del plasminógeno ocasionaría un incremento de la actividad fibrinolítica ${ }^{5}$.

Cuando la trombocitopenia es grave, el mecanismo estaría mediado por la producción de autoanticuerpos e inmunocomplejos, ocasionando una destrucción acelerada de plaquetas semejante a la PTI. También se ha propuesto la afectación directa de los megacariocitos por parte del SARS-CoV-2 a través del receptor CD13 en la médula ósea ${ }^{6,7}$.

La COVID-19 es una enfermedad incipiente de la cual aún se desconocen muchos datos y formas de presentación. Ante un paciente con PTI debemos descartar las posibles etiologías. Uno de los virus que pueden desencadenar esta afectación inmunitaria, y debemos sospechar, es el SARS-CoV-2.

En nuestro paciente, la trombocitopenia no se produjo en fases avanzadas o graves de la infección como consecuencia de una coagulopatía intravascular diseminada (no tenía alargamiento del tiempo de coagulación TP, TTPA, ni disminución de fibrinógeno), sino en un contexto de una neumonía sin criterios de gravedad. La elevación de los niveles de lgG total, con la presencia de lgG específicas anti-SARS-CoV-2, apoyaría el mecanismo inmunológico secundario a un aumento de la destrucción mediada por anticuerpos contra dicho virus.

\section{Bibliografía}

1. Guan WJ, Ni ZY, Hu Y, Liang WH, Ou C, et al. Clinical characteristics of coronavirus disease 2019 in China. N Engl J Med. 2020; 382: 1708-1720. doi: 10.1056/ NEJMoa2002032

2. Zulfiqar AA, Lorenzo-Villalba N, Hassler P, Andrés E. Immune thrombocytopenic purpura in a patient with Covid-19. N Engl J Med. 2020 Apr 30; 382(18): e43. doi: 10.1056/NEJMc2010472.

3. Yang M, Margaret HL Ng, Li CK. Thrombocytopenia in patients with severe acute respiratory syndrome (review). Hematology. 2005; 10(2): 101-105. doi: 10.1080/10245330400026170.

4. Tang N, Li D, Wang X, Sun Z. Abnormal coagulation parameters are associated with poor prognosis in patients with novel coronavirus pneumonia. JThromb Haemost. 2020; 18: 844-847. doi: 10.1111/jth.14768.

5. Lillicrap D. Disseminated intravascular coagulation in patients with 2019nCoV pneumonia. J Thromb Haemost. 2020; 18: 786-787. doi: 10.1111/ jth.14781.

6. Amgalan A, Othman M. Exploring possible mechanisms for COVID-19 induced thrombocytopenia: Unanswered questions. Department of Biomedical and Molecular Sciences School of Medicine, Queen's University, Canada. doi: 10.1111/JTH.14832.

7. Xu P, Zhou Q, Xu J. Mechanism of thrombocytopenia in COVID-19 patients. Ann Hematol. 2020 Apr 15; 1-4. doi: 10.1007/s00277-020-04019-0. 